\title{
O papel do intelectual no México nos anos 1970 e 1980: polêmicas nas revistas Plural e Vuelta.
}

\author{
Sílvia Cezar Miskulin ${ }^{1}$
}

Resumo: Plural e Vuelta reuniram um grupo de intelectuais mexicanos, dirigidos por Octavio Paz, diretor das publicações. Nos anos 1970 e 1980, a sociedade mexicana passou por decisivas discussões, que repercutiram nas revistas. A forte repressão ao movimento estudantil de 1968 fez com que muitos intelectuais, entre eles colaboradores das revistas, criticassem os Presidentes do PRI. No entanto, as revistas Plural e Vuelta abriram espaços para polêmicas e alguns escritores defenderam a participação e apoio aos governos do PRI. O debate sobre o papel do intelectual esteve sempre presente nessas publicações e prosseguiu ao longo dos anos oitenta no México.

Palavras-chave: intelectual, México, revistas.

\begin{abstract}
Plural and Vuelta brought together a group of Mexican intellectuals led by the magazine director, Octavio Paz. In the nineteen seventies and eighties, the Mexican society engaged in different debates, which resonated in these publications. A strong repression to the student movement in 1968 raised criticism against PRI Presidents among intellectuals. However, Plural and Vuelta provided space to controversial articles and a few writers advocated participation in and support to PRI administration. A debate about the role of Mexican intellectuals has always been present in these publications, which continued into the nineteen eighties.
\end{abstract}

Key Words: Intellectuals, Mexico, magazines.

As revistas Plural e Vuelta reuniram um grupo significativo de intelectuais mexicanos, liderados pela presença de Octavio Paz, diretor das publicações. Nos anos setenta e oitenta, a sociedade mexicana realizou importantes debates que estiveram

\footnotetext{
${ }^{1}$ Pós-Doutora em História da USP e professora da Universidade de Mogi das Cruzes. Este artigo faz parte da pesquisa de Pós-Doutorado realizada no Departamento de História da USP, com bolsa da Fapesp. Email: silmiskulin@uol.com.br
} 
presentes nas páginas das revistas. Nessas publicações, discutiu-se o papel do intelectual na sociedade da época, com muitas polêmicas sobre independência ou apoio aos governos dirigidos pelo PRI (Partido Revolucionário Institucional), ao longo dessas duas décadas.

A forte repressão governamental ao movimento estudantil de 1968 fez com que muitos intelectuais, entre eles, colaboradores das revistas, criticassem os sucessivos governos presidenciais do PRI. No entanto, as revistas Plural e Vuelta abriram espaços para controvérsias e alguns escritores defenderam a participação e apoio aos governos do PRI.

A revista Plural, suplemento cultural mensal do jornal Excelsior, editou seu primeiro número em outubro de 1971. O diretor do diário, Julio Scherer García, convidou Octavio Paz para dirigir um suplemento cultural semanal de Excelsior, que aceitou a proposta desde que a revista tivesse periodicidade mensal.

Desde o início, o objetivo de Plural era ser uma publicação crítica, dedicada à literatura, mas também à história e à política (PAZ, 2001, p. 16). Escolhido por Octavio Paz e Julio Scherer García, o nome da revista era uma referência à necessidade de o México abrir-se naquele momento para a pluralidade (SCHERER GARCÍA, 2001, p. 3). Em uma entrevista publicada no jornal Excelsior, em 1972, Paz definiu bem precisamente o perfil da revista: "Eu diria que Plural é uma revista latino-americana a partir de México e aberta ao mundo" (PAZ, 2001b, p. 8). ${ }^{2}$

Octavio Paz reuniu muitos intelectuais que colaboravam com a revista. $\mathrm{O}$ primeiro secretário de redação foi Tomás Segovia, função posteriormente realizada por Kazuya Sakai, depois, por José de la Colina, e, por último, pelo uruguaio Danúbio Torres Fierro. Em 1975, mudanças ocorreram entre os dirigentes de Plural, organizando-se um conselho de redação, cujos participantes foram José de la Colina, Salvador Elizondo, Juan García Ponce, Alejandro Rossi, Tomás Segovia e Gabriel Zaid. No entanto, a presença de Paz em Plural era muito marcante, sua figura e projeção intelectual definiam os principais marcos e a linha editorial da publicação.

Em sua maioria escritores que já possuíam obras publicadas, os colaboradores da revista congregaram-se no trabalho coletivo sob a direção decisiva de Paz. Muitos já haviam colaborado ou sido, até mesmo, diretores da Revista Mexicana de Literatura,

\footnotetext{
${ }^{2}$ As traduções das citações aqui presentes são de própria autoria.
} 
editada em meados dos anos 50 e dirigida na primeira fase por Carlos Fuentes e Emmanuel Carballo, e, na segunda, por Juan García Ponce e Tomás Segovia, ${ }^{3}$

A revista Plural contou ainda com muitos colaboradores internacionais, como, por exemplo, Juan Goytisolo e Carlos Barral, e principalmente com muitos escritores que acompanharam o boom da literatura latino-americana nos anos 1970, entre os quais, Emir Rodríguez Monegal, Angel Rama, Guillermo Cabrera Infante, Severo Sarduy, Mario Vargas Llosa, Haroldo e Augusto de Campos, Manuel Puig, Jorge Edwards, e, em menor medida, Julio Cortázar e Gabriel García Márquez, devido às suas relações próximas ao governo cubano. ${ }^{4}$ Plural possuía uma "vocação hispano-americana", como reconheceu seu próprio diretor (PAZ, 2001a, p. 20); vocação esta que seria seguida pela revista Vuelta, como mostrarei a seguir.

Logo que saiu o primeiro número, a revista repercutiu no meio intelectual mexicano, pois Octavio Paz já possuía uma obra com grandes méritos literários. Havia pouco que Paz abandonara a carreira diplomática, ao renunciar à embaixada na Índia, em razão da matança de estudantes ocorrida em 2 de outubro de 1968, na praça de Tlatelolco, durante o governo de Gustavo Díaz Ordaz do PRI. As forças repressivas governamentais combateram duramente o movimento estudantil, com prisões e assassinatos de centenas de manifestantes às vésperas dos Jogos Olímpicos, que seriam realizados pouco tempo depois na cidade do México (MISKULIN, 2008).

Os participantes de Plural foram muito impactados pelos episódios de 1968, que marcaram o rompimento entre muitos intelectuais e o Estado no México (PAZ, 1999, p. 21; MARQUES ACEVEDO, 1991). Os acontecimentos de 1968 no México ocasionaram não apenas uma grande cisão entre os intelectuais críticos e os governos dirigidos pelo PRI, mas também muitas discussões entre os colaboradores de Plural sobre a conduta dos intelectuais perante o poder no decorrer dos anos 1970 e 1980.

A polêmica teve início com a publicação do artigo de Carlos Fuentes em Plural, em agosto de 1972, quando defendeu a participação dos intelectuais no governo de Luís Echeverría, que sucedia o Presidente Díaz Ordáz, governante do país em 1968 (FUENTES, 1972, p. 3-9). No momento da repressão aos estudantes, Echeverría era secretário de governo, cargo que equivalia no México a ministro do Interior. Fuentes

\footnotetext{
${ }^{3}$ Segundo Perales Contreras, a Revista Mexicana de Literatura teria surgido a partir de reuniões realizadas na casa de Octavio Paz, que incentivou a sua criação (PIACENTINI, 1996, p. 105).

${ }^{4}$ As posições dos intelectuais latino-americanos que pertenceram ao boom, e suas relações e polêmicas com o governo cubano nos anos 60 e 70 foram exaustivamente analisadas na tese de Adriane Vidal Costa (COSTA, 2009).
}

Revista Eletrônica da ANPHLAC, n.10, p. 126-145, jan./jun. 2011. http://revista.anphlac.org.br/index.php/revista 
havia declarado, pouco antes, em uma entrevista nos Estados Unidos, a polêmica frase "dejar aislado a Luis Echeverría, crimen histórico de intelectuales", advogando a necessidade de participação política aberta dos escritores na vida pública (KING, 2008, p. 31). No artigo publicado em Plural, Fuentes reconhecia a crise que havia se instalado no país em 1968, e escancarava o racha do sistema mexicano e de suas organizações, que não respondiam às exigências de avanço democrático no país, de maior justiça social e de ampliação das liberdades políticas (FUENTES, 1972a, p. 4).

No entanto, Carlos Fuentes ressaltou que o governo de Echeverría agia corretamente em sua política externa, ao prestar solidariedade ao governo de Allende e refinar o cobre chileno, além de não acatar o bloqueio econômico imposto pelos Estados Unidos contra Cuba exportando para a ilha produtos como ônibus, feijão e cimento. Fuentes também destacou outro enorme acerto de Echeverría, que não seguia o caminho desejado pelo governo dos Estados Unidos, que conseguira no Brasil aquilo que não havia no México: "uma fachada de prosperidade" econômica, "em troca de repressão política" (FUENTES, 1972a, p. 6).

Para Fuentes, o ideal para o México seria:

\begin{abstract}
la posibilidad de lo que Octavio Paz llama una 'alianza popular independiente' que empiece a promover, nacionalmente, otro tipo de vida política, la que corresponda a las estructuras del siglo XXI: el socialismo democrático, el socialismo sin enajenaciones al canon estalinista, la fusión, in situ, de la democracia política y la democracia económica. La nueva y vieja democracia mexicana que, esta vez, recobre todos los cabos sueltos y las promesas suspendidas que la revolución de 1910 no pudo reintegrar a nuestra vida colectiva (FUENTES, 1972a, p.8).
\end{abstract}

Sua defesa do socialismo democrático no México parecia contraditória com a confiança e o apoio ao governo de Luis Echeverría. Carlos Fuentes assumiu, inclusive, a versão formulada pelo próprio governo para justificar a nova matança de estudantes em Jueves de Corpus, em 10 de junho de 1971. Segundo a versão do governo mexicano, endossada por Fuentes, as forças conservadoras e reacionárias do país haviam se unido para reprimir o movimento estudantil e estigmatizar o governo, desacreditando-o em sua tentativa de democratização do regime.

No dia 10 de junho de 1971, jueves, que coincidia com a festa de Corpus Christi, os estudantes da Cidade do México manifestaram-se em apoio aos alunos da Universidad Autónoma de Nueva León. Era a primeira manifestação estudantil que ganhava as ruas desde os episódios trágicos de 1968. Um grupo de elite do Exército

Revista Eletrônica da ANPHLAC, n.10, p. 126-145, jan./jun. 2011. http://revista.anphlac.org.br/index.php/revista 
mexicano, Los Halcones, reprimiu brutalmente a manifestação e assassinou inúmeros estudantes. A matança revelou os limites da proposta de abertura do governo de Luis Echeverría e dividiu os intelectuais entre aqueles que apoiavam o governo e os que exigiam investigação e justiça. Segundo estudo de Malva Flores, apenas em 29 de novembro de 2006, mais de 32 anos depois, Echeverría foi declarado culpado por delito de genocídio, mas, em 20 de março de 2007, um Tribunal Federal anulou o auto formal de prisão (FLORES, 2010, p. 519).

Carlos Fuentes salientou aspectos que considerava positivos da administração de Echeverría, como a "liberação de presos políticos", a "modernização do aparato democrático", a "direção honesta dos fundos públicos" e "atos de justiça para camponeses e grupos indígenas", além da proximidade de Echeverría com diversos setores da população, comparando-o a Cárdenas. Somada à avaliação bastante questionável do governo, Carlos Fuentes elogiou a política de democratização implementada por Echeverría e acusou de crime histórico aqueles que resolvessem se abster nesse projeto político, pois acreditava que era tarefa dos intelectuais dar "apoio crítico" ao governo para impedir um "golpe de Estado da extrema direita", fato que posteriormente viemos a saber nunca ocorreu (FUENTES, 1972a, p. 9).

Em resposta ao polêmico artigo de Fuentes, Plural publicou artigos de Gabriel Zaid e de Octavio Paz, além de todo o suplemento do número 13, chamado Los escritores y la política, cujas matérias abordaram a relação entre os intelectuais e o Estado.

Importante colaborador de Plural, Gabriel Zaid dialogou abertamente com o artigo de Fuentes ao intitular seu texto de "Carta a Carlos Fuentes", e afirmou claramente, em diversos momentos, a necessidade de que a "vida pública no México fosse verdadeiramente pública" (ZAID, 1972a, p. 52). Para Zaid, o juízo de Fuentes sobre o presidente Luis Echeverría, reputando-o um homem "patriota e honesto", não poderia ser um argumento público, pois Porfírio Díaz também havia se considerado patriota e honesto; tratava-se, pois, de um argumento privado. Para Zaid, os funcionários públicos deveriam ser julgados por seus atos públicos, incluídos seus atos de omissão. Gabriel Zaid relembrou que, em 1968, Echeverría, então "Secretario de Gobernación", não renunciou, nem aproveitou seu cargo posterior de presidente para apurar as responsabilidades pelas mortes ocorridas em Tlatelolco. Embora Echeverría tivesse se indignado publicamente com a "matança de Corpus", mais de um ano depois 
da repressão não se sabia quem eram os responsáveis, tampouco, obviamente, havia ocorrido julgamento dos culpados (ZAID, 1972a, p. 52).

O debate sobre o papel do escritor independente também foi abordado por Zaid, pois, em sua visão, este não deveria se confundir em hipótese alguma com o Executivo. O compromisso do intelectual corresponderia a criticar publicamente o governo de Echeverría, cobrando promessas públicas que não haviam sido cumpridas. A lealdade do escritor seria, portanto, com o seu público e com a defesa do "quarto poder", "uma verdadeira vida pública" (ZAID, 1972a, p. 52). Nesse sentido, Zaid cobrava explicitamente a postura política de Carlos Fuentes, pois seu exemplo era muito negativo, e, aos olhos do público, não restava nenhuma diferença entre o intelectual e um senador, deixando mais difícil a situação dos escritores independentes (ZAID, 1972a, p. 53).

Octavio Paz escreveu, por sua vez, o artigo "La letra y el cetro", que apresentava o número 13 da revista Plural, dedicado ao tema dos escritores e o poder. Definiu desde logo sua preferência por utilizar o termo escritores, ao invés de intelectuais: primeiro porque a revista fazia parte do campo da literatura e não da ciência ou da técnica, e segundo porque, apesar de quase todos os escritores serem intelectuais, a recíproca não era verdadeira (PAZ, 1972a, p. 7).

A apresentação destacava que aquele número da publicação estava totalmente voltado para a relação dos escritores com a política. Paz ressaltou ainda que a revista trazia a edição de um poema do escritor russo Osip Mandelstam, que fazia uma sátira ao governo de Stálin, em 1933. Osip foi preso e enviado aos campos de concentração na Sibéria, onde morreu, mas segundo Paz: "Con esse poema que le costó la vida, Mandelstam salvó el honor de la poesia del siglo XX, manchada por tantos himnos y odas a la gloria de Stalin" (PAZ, 1972a, p. 7). No artigo "La letra y el cetro", Paz esclareceu como foi elaborado aquele suplemento. Como diretor de Plural, ele escreveu um texto inicial breve, enviado aos outros escritores participantes, que teriam direito de comentá-lo e expressar a sua opinião, cada um publicando, assim, duas vezes no debate.

Ao inaugurar o suplemento 13 da revista Plural, intitulado México 1972 os escritores e a política, Octavio Paz explicou a quebra do sistema político mexicano, cujos eventos de 2 de outubro de 1968 e de 10 de junho de 1971, em referência ao massacre de estudantes na praça de Tlatelolco e no Jueves de Corpus, eram "a prova de sangue da gravidade da crise" (PAZ, 1972b, p. 21). Fez uma dura crítica ao dualismo do 
sistema mexicano, que, baseado na permanência do PRI no governo, exercia um "monopólio da vida pública", enquanto a única possibilidade de mudança e renovação ocorria a cada seis anos com a eleição presidencial. Paz criticou ainda o exagerado poder do Executivo no México, que não possuía nenhuma limitação, tanto por parte do Legislativo, quanto do Judiciário, e comparou a situação do país com a vivida na ditadura da Roma antiga (PAZ, 1972b, p. 21).

Segundo Paz, a situação do México diferia dos demais países da América Latina, pois não se vivia sob ditadura militar ou sob o domínio do caudilhismo, embora definisse os presidentes mexicanos como "ditadores constitucionais". Fruto da Revolução Mexicana, foi fundado em 1929 o Partido Nacional Revolucionario, que se transformou em Partido de la Revolución Mexicana e, posteriormente, Partido Revolucionario Institucional. Paz relembrou que essas mudanças representavam a conversão de uma facção revolucionária e nacionalista em uma gigantesca burocracia conservadora, uma verdadeira "máquina de controle e manipulação das massas".

O PRI vivia uma verdadeira simbiose com o Estado e se nutria da relação com as massas para manter sua fonte de poder, de mobilidade e de ascensão social. $\mathrm{O}$ mais interessante da análise de Paz era sua comparação da situação mexicana com a soviética:

\footnotetext{
Las burocracias políticas del siglo XX, desde la soviética hasta la mexicana, esperan todavía una descripción científica: no son ni una clase ni una casta pero poseen características de ambas. A diferencia de las burocracias comunistas, la nuestra no controla la economía nacional sino que se inserta en un contexto capitalista y, hasta cierto punto, democrático. Esta doble circunstancia y la ausencia de una ortodoxia ideológica explican su relativo liberalismo y su relativa inestabilidad. También su relativa independencia (PAZ, 1972b, p. 21-22).
}

A crise do PRI devia-se ao fato de o partido querer conservar a aliança com a burguesia e, ao mesmo tempo, "controlar as massas", mantendo sua identidade, o que gerava uma contradição que, de acordo com a visão de Paz, se expressava na política de "abertura democrática". Em seu texto no suplemento de Plural, Paz via uma solução para o futuro do México, que consistiria em um "movimento popular, independente e democrático", que agruparia todos os setores "oprimidos e dissidentes" do país em um “programa mínimo comum”. No entanto, ele não elaborou nem deixou claro qual seria este programa necessário para o México sair da crise.

Revista Eletrônica da ANPHLAC, n.10, p. 126-145, jan./jun. 2011. http://revista.anphlac.org.br/index.php/revista 
O papel de escritor, segundo Paz, era preservar sua "marginalidade frente ao Estado, aos partidos, às ideologias e à sociedade", visto que tinha uma voz crítica em relação ao mundo e a si próprio. Para Paz, o escritor "desenha com suas palavras uma falha, uma fissura", e a literatura era capaz de "colocar a nu os chefes de poder e humanizá-los" (PAZ, 1972b, p. 22). A sua posição sobre o papel do intelectual não pressupunha o engajamento diante de causas sociais, como, por exemplo, a perspectiva defendida por Jean-Paul Sartre, de total comprometimento do escritor com as questões de seu tempo. Nesse momento, a visão de Paz — defensor de um distanciamento dos escritores tanto do Estado quanto das ideologias - aproximava-se de uma noção de intelectual liberal, sem a necessidade de firmar compromissos e cuja única causa era a "liberdade" (LOAEZA, 2009, p. 167). Segundo estudo de Soledad Loaeza, com sua postura de intelectual liberal, Paz provocou a reação dos jovens da geração de 1968, que acreditavam no compromisso revolucionário dos escritores e artistas (LOAEZA, 2009, p. 167).

Nesse mesmo suplemento, a colaboração de Gabriel Zaid chamou atenção, já que apontava a certeira previsão de que, nos anos de 2000 ou 2006, o México teria um governador ou um presidente não pertencente ao PRI. Zaid também não acreditava que, para a solução política do país, os intelectuais devessem formar um novo partido, pois seria como "arar no mar" (ZAID, 1972b, p. 22). Em sua visão, os intelectuais deveriam se concentrar na criação de uma "discussão pública independente" através da palavra impressa, como a que ocorria por meio do jornal Excelsior. O exemplo de Daniel Cosío Villegas foi lembrado, pois, na opinião de Gabriel Zaid, a criação da editora Fondo de Cultura Económica havia feito mais pela democratização do México do que o Partido Popular Socialista, ou ainda o Partido de Acción Nacional.

O escritor Jaime García Terrés iniciou sua colaboração informando que já havia participado da direção coletiva da revista El Espectador. Afirmou a necessidade e a urgência de transformar a vida, e revelou que aplaudia a juventude por ainda possuir tais anseios. García Terrés deixou bem claro que não era partidário do "esteticismo", pois concebia a literatura como "uma tarefa revolucionária" e com uma inelutável função crítica. Segundo ele, a opinião política do escritor partia de suas próprias ambiguidades, oscilando entre "as paixões" e "as incertezas", o que gerava uma desconfiança não só dos grupos reacionários, como também da esquerda militante. No entanto, apesar de defender a postura crítica do escritor, Jaime García Terrés reconhecia que era raro um 
"escritor maduro" que vivesse às suas próprias expensas no México, sem relações diretas ou indiretas com o Estado (GARCÍA TERRÉS, 1972, p. 23).

Outro colaborador de Plural que participou, nesse suplemento, do debate sobre o papel do escritor foi Luis Villoro. Sua análise da situação política mexicana também frisou a importância da burocracia, e de seu sistema de controle popular que buscava restaurar um "Estado populista" com medidas de democratização e promessas de benefícios que, embora pretendessem atingir as classes médias e populares, tinham limites. Villoro coincidia com a avaliação de Octavio Paz quanto à necessidade do "nascimento de um movimento popular independente", que, em sua opinião, seria "revolucionário" e não "violento", preparando as condições para as transformações e o surgimento de "organizações de massas independentes" (VILLORO, 1972, p. 23). Interessante notar que seu parecer sobre o papel do escritor diferia do produzido por Octavio Paz, já que ele não compartia da visão do escritor dotado de uma "pureza ideológica" ou como um "testemunho desinteressado".

Para Luis Villoro, por mais que a vocação do escritor fosse "não representar ninguém", partindo de uma posição independente e "desprendida", a situação acabava por envolvê-lo. O escritor, a seu ver, ao se iludir "com as declarações progressistas dos políticos", esquecia da realidade econômica e social que o cercava. Tais declarações pareciam uma crítica clara às opiniões e atitudes de Carlos Fuentes. Por fim, defendia que a vocação do escritor estava justamente na liberdade e universalidade de pensamento.

Tomás Segovia teve um papel de destaque na publicação de Plural, como primeiro secretário de redação e, posteriormente, membro do conselho de redação. Foi, sem dúvida, um importante interlocutor de Octavio Paz enquanto este residiu fora do país (na Índia e na Europa) nos anos 60, já que a troca de cartas entre os dois escritores delineou os projetos e as perspectivas para a elaboração da revista que depois se concretizou em Plural (PAZ, 2008). Segovia participou no debate defendendo a "preservação da marginalidade do escritor" e também a luta contra a violência reacionária. Em sua reflexão, os intelectuais eram aqueles que criticavam o poder, sem dele usufruir.

A literatura deveria "falar de política" e criticá-la, mas sem "fazer política", pois, para Tomás Segovia, o intelectual permanecia em sua marginalidade com sua capacidade crítica: 
así el escritor puede mediatizar programas y acciones pero no al gobierno y al partido. Dicho de otra manera aún, sus soluciones y programas no deben dirigirse al gobierno sino a algo tan incorrecto como el "pueblo" - o si se quiere a nadie: en formas de alternativas frente al poder y no de programas del poder; así cuando éste adopte algunas (o coincida con ellas) puede darle su aplauso sin comprometerse con él (SEGOVIA, 1972, p. 24).

No suplemento 13 de Plural, em Los escritores y la política, Carlos Monsiváis apontou para uma crítica mais radical, em que questionou duramente a confiança de Fernando Benítez e Carlos Fuentes no presidente Echeverría. Relembrou que esse governo tinha o peso da "matança de 10 de junho de 1971", cuja investigação dos responsáveis deveria começar justamente quando Echeverría iniciou sua política de "abertura democrática". Criticou ainda que tal abertura era meramente formal, pois, na prática, buscava-se o esquecimento de "crimes coletivos" e de golpes políticos a fim de restabelecer o equilíbrio do regime, além de uma "liberdade de imprensa seletiva e condicional" (MONSIVÁIS, 1972, p. 24). No entanto, Carlos Monsiváis fez questão de dizer que o México não era o Brasil e não vivia "uma ditadura", embora o país se encontrasse numa situação de dependência e falta de liberdade.

Monsiváis rechaçou de forma "emocional cultural e política" o lema de "ordem e progresso" vigente no México e propôs uma saída socialista para a crise do país:

creo en el único porvenir legítimo de México: el socialismo, un socialismo desestalinizado, sin campos de concentración diseñados como unidades militares de ayuda a la producción, sin persecuciones de minorías, sin el sacrificio de los derechos democráticos elementales. Un socialismo que, por lo demás, resulta inevitable por urgente (MONSIVÁIS, 1972, p. 25).

Para finalizar, Carlos Monsiváis definiu que seu papel como escritor e jornalista era contribuir para que um impulso democrático surgisse no México desde baixo, a partir de "grupos operários dissidentes", da "radicalização do movimento estudantill, da resistência de "núcleos camponeses independentes", que teriam que se desenvolver e se transformar em "militância organizada", para lutar por um futuro socialista. O livro de Jaime Sánchez Susarrey sobre o debate político e intelectual no México mostrou que Carlos Moinsiváis tinha uma postura mais explícita contra os intelectuais liberais nas páginas da publicação La cultura en México ${ }^{5}$, em que defendeu a visão do intelectual

\footnotetext{
${ }^{5}$ O suplemento La cultura em México, que fazia parte do semanário Siempre!, foi dirigido por Fernando Benítez, com a importante colaboração de Carlos Monsiváis, chefe de redação por um período. Ao analisar em seu livro a publicação e sua relação com o movimento de 1968, Jorge Volpi definiu que $L a$
}

Revista Eletrônica da ANPHLAC, n.10, p. 126-145, jan./jun. 2011. http://revista.anphlac.org.br/index.php/revista 
"orgânico" de Gramsci, respaldando a luta popular contra a dependência e o subdesenvolvimento (MONSIVÁIS apud SANCHEZ SUSAREY, 1993).

Outra contribuição ao suplemento foi de José Emilio Pacheco, que manifestou sua desconfiança na proposta de "abertura política" do governo de Echeverría, já que esta não era visível "no campo, nas fábricas ou nos sindicatos". Acusou ainda que a investigação sobre os acontecimentos de 10 de junho de 1971 não seria completa se não começasse com a investigação sobre o 2 de outubro de 1968, quando Echeverría era Secretario de Gobernación e "supremo responsável dos corpos policiais" que realizaram a repressão (PACHECO, 1972, p. 25).

Um balanço da vida intelectual do país foi elaborado por Pacheco, que mostrou como a unidade dos intelectuais ocorrida em 1968, com a oposição ao governo devido ao massacre do movimento estudantil, havia se rompido em 1972, a partir do apoio de intelectuais como Carlos Fuentes ao governo do PRI (PACHECO, 1972, p. 26). Para José Emilio Pacheco, o apoio de Fuentes a Echeverría abria uma crise na relação de todos os escritores com o público, sobretudo, com os estudantes, que sofreram a repressão governamental em 1968 e 1971. O escritor frisou, de todo modo, a necessidade de independência dos intelectuais em frente ao Estado.

Ao refletir sobre a responsabilidade do escritor, Juan García Ponce relatou, no suplemento, como durante muito tempo foi indiferente politicamente, e que sua mudança viria a partir de 1968, um "ano axial”. García Ponce também denunciou as "modernas sociedades autoritárias", que submetiam os dissidentes a tratamento psiquiátrico como forma de repressão, mas concluiu que "ninguém poderia fazer calar a literatura", pois sua voz sempre reaparece (GARCÍA PONCE, 1972, p.26).

A decisão de Carlos Fuentes de participar do governo de Echeverría causou, de fato, uma grande cisão no meio intelectual mexicano em 1972, da mesma forma que o posicionamento diante do "caso Padilla" já havia dividido os escritores latinoamericanos em 1971, alterando, para muitos, definitivamente a relação com o governo cubano. ${ }^{6}$ Fuentes participou ativamente do sexênio de Echeverría, não apenas como embaixador na França, cargo que assumiu em 1975, mas também em reuniões do IEPES

cultura em México era um "baluarte da liberdade de expressão intelectual e artística" daquela geração. Para Volpi, Siempre! teve a "reputação de ser a publicação política mais importante e plural nos anos 60 " (VOLPI, 2008, p. 50-51).

${ }^{6}$ Em abril de 1971, o escritor cubano Heberto Padilla foi preso e obrigado a fazer uma confissão pública, reconhecendo atitudes contrarrevolucionárias e acusando ainda outros escritores e amigos. $\mathrm{O}$ episódio ficou conhecido como "caso Padilla" e teve ampla repercussão no campo intelectual (MISKULIN, 2009).

Revista Eletrônica da ANPHLAC, n.10, p. 126-145, jan./jun. 2011.

http://revista.anphlac.org.br/index.php/revista 
do PRI, onde segundo Sergio Marques Acevedo, seus textos serviram de base para debates sobre a política nacional (MARQUES ACEVEDO, 1991, p. LXXIV). Fuentes acusou muitos intelectuais de Plural de fazer uma crítica liberal ao governo de Echeverría, já que, em sua opinião, se tratava de um "governo de esquerda" (FUENTES, 1972b, p. 28-29), avaliação bastante questionada pelos colaboradores da publicação.

Após a edição desse suplemento, tornou-se evidente que a revista Plural era uma publicação pluralista. O debate sobre o papel dos intelectuais, a política e o poder revelou que a maioria de seus colaboradores questionava o governo do PRI e o presidente Echeverría. No entanto, apesar de sua posição e colaboração junto ao governo, Carlos Fuentes continuou tendo espaço na publicação.

Como se sabe, a presidência de Luis Echeverría tentava realizar uma aparente "abertura democrática" no México, e queria cooptar os intelectuais para participar do governo. Mesmo assim, Echeverría ordenou uma intervenção no jornal Excelsior, diário do qual Plural fazia parte como suplemento. Em 8 de julho de 1976, o editor chefe e mais seis membros do jornal acabaram expulsos graças às pressões governamentais, pois haviam divulgado muitas críticas ao presidente.

Após a publicação do número 58, em julho de 1976, Octavio Paz e os demais colaboradores da revista renunciaram a direção e elaboração de Plural, em solidariedade a Julio Scherer García e outros jornalistas expulsos (MONTOYA RAMÍREZ, 1989, p. 119). Na redação da revista restaram apenas os móveis e a máquina de escrever, como testemunhou posteriormente Paz (PAZ, 2001a, p. 21). Plural continuou sendo publicada com diferentes escritores, sob a direção de Roberto Rodríguez Baños. Julio Scherer e outros jornalistas de Excelsior prepararam um manifesto e um ato público contra seus desligamentos do jornal, ocasião em que anunciaram o surgimento de Proceso, uma nova revista semanal de política e informação que circula até hoje no México sob a direção de Julio Scherer García. ${ }^{7}$ Nessa época, surgiu ainda o jornal diário Unomasuno, mais relacionado a intelectuais de esquerda (PIACENTINI, 1996, p. 102).

Uma nova revista também foi organizada por Paz, em dezembro de 1976. Denominada Vuelta, contou com a participação da maior parte dos colaboradores de

\footnotetext{
${ }^{7}$ Segundo Octavio Paz, ele não assinou este manifesto contra a expulsão dos jornalistas de Excelsior, pois não aceitaram que outros membros do conselho de redação de Plural também o fizessem. No ato publico, não falaram do apoio político de Plural aos desligamentos em Excelsior, o que afastou ainda mais os dois grupos de intelectuais (PAZ, 2001a, p.21).
}

Revista Eletrônica da ANPHLAC, n.10, p. 126-145, jan./jun. 2011. http://revista.anphlac.org.br/index.php/revista 
Plural: Alejandro Rossi, diretor suplente da publicação, José de la Colina, secretário de redação, e Abel Quezada Rueda, diretor artístico. Do conselho de redação tomaram parte José de La Colina, Salvador Elizondo, Juan García Ponce, Alejandro Rossi, Kazuya Sakai, Tomás Segovia e Gabriel Zaid.

No primeiro número, Vuelta trazia na capa as cores da bandeira mexicana. Octavio Paz evidenciou que a nova publicação surgia após o desaparecimento da revista Plural e pontuou o significado de seu nome: "Vuelta quer dizer regresso ao ponto de partida e, também, mudança, transformações. Dois sentidos contraditórios? Mas também complementários: dois aspectos da mesma realidade, como a noite e o dia" (PAZ, 1976, p. 4).

A revista Vuelta teve não apenas o mesmo grupo de colaboradores de Plural, como também o idêntico perfil cosmopolita e latino-americanista, abordando tanto temas culturais quanto políticos. Para Octavio Paz, Vuelta inovava porque era financiada exclusivamente por assinantes, leitores e anúncios, sem ser dependente de qualquer instituição pública ou privada, como tinha sido Plural, que circulava conjuntamente com o jornal Excelsior (PAZ, 2001a, p. 21). Mais uma vez, a figura de Paz destacava-se na publicação, não só por cuidar dos principais editoriais e definir as diretrizes da revista, mas também devido à grande projeção que sua obra já alcançara nessa época.

Enrique Krauze desempenhou um importante papel na publicação. Ele já havia colaborado com Plural, mas, em Vuelta, assumiu a função de secretário de redação a partir do número 5, em abril de 1977, com a saída de Alejandro Rossi e José de la Colina da secretaria de redação. Posteriormente, em dezembro de 1981, tornou-se subdiretor da revista, a partir do número 61. Engenheiro e historiador, Krauze deu a revista uma cara de empreendimento empresarial: organizou uma editora ligada ao grupo - a editora Vuelta - e promoveu ainda uma série de encontros televisivos, que, posteriormente, seriam transformados em livros (CASTAÑóN, 1999, p. 518).

A partir do número 18, em maio de 1978, a cubana Julieta Campos, a uruguaia Ulalume González de León e o escritor mexicano Jorge Ibargüengoitia passaram a integrar o conselho de redação de Vuelta. Em agosto de 1986, no número 117, ocorreram mudanças importantes, com a criação de um conselho de colaboração e a extinção do conselho de redação, cujos membros foram todos incorporados no novo 
conselho da revista. Composto por 36 nomes, o conselho de colaboração reuniu ainda os escritores latino-americanos e espanhóis que mais contribuíram com a publicação. ${ }^{8}$

Fundada em 1976, Vuelta circulou por mais de duas décadas até 1998, ano em que morreu Paz (n. 261, agosto-setembro de 1998). Por sua longa duração, contou com inúmeros colaboradores e diferentes equipes de intelectuais em sua direção. Apesar de ter surgido como uma publicação cultural, temas políticos foram sempre abordados, o que revelava uma concepção ampla de cultura por parte de seus diretores e colaboradores (KING, 2008, p. 30-39; KING, 2007).

Vuelta também seguiu com o debate e reflexão sobre as relações entre os intelectuais e os governos do PRI no México, publicando polêmicas a respeito do apoio ou participação de certos intelectuais em esferas governamentais nos anos 70 e 80 .

Em 1988, ocorreu um episódio decisivo marcando o início de uma nova etapa na história do México, que seria alvo de debate na publicação. Tratava-se das eleições presidenciais em que concorreram três candidatos: Carlos Salinas de Gortari, do PRI, Manuel Clouthier, pelo PAN, e Cuauhtémoc Cárdenas, pela Frente Cardenista de Reconstrución Nacional (reunião de partidos e grupos de esquerda). O resultado das eleições foi bastante controverso, apesar da vitória de Salinas de Gortari. Acusações de fraude surgiram e revelaram que Cárdenas teria sido o verdadeiro ganhador das eleições.

Essa situação política gerou um debate sobre a legitimidade do processo eleitoral e o significado da "democracia" no México. Muitos intelectuais que se manifestaram em Vuelta reforçaram a demanda por democracia e analisaram o resultado das eleições como forma de um setor social expressar seu desejo por uma "transição democrática pacífica". Nesse sentido, o artigo de Jaime Sánchez Susarrey mostrou que uma parte do eleitorado queria o fim do PRI como partido único no poder, e que o último processo eleitoral tinha suspeita de "ilegitimidade" (SÁNCHEZ SUSARREY, 1988, p. 62). Sánchez Susarrey acreditava que o México vivia uma crise política em seu regime e que apenas a "alternância de partidos e a derrota eleitoral do PRI marcariam a chegada da democracia" (SÁNCHEZ SUSARREY, 1988, p. 62).

\footnotetext{
${ }^{8}$ Do conselho de redação participaram: Adolfo Bioy Casares, Guillermo Cabrera Infante, Julieta Campos, Juan Gustavo Cobo Borda, Pablo Antonio Cuadra, Haroldo de Campos, José de la Colina, Jorge Edwards, Slavador Elizondo, Enrique Fierro, Juan García Ponce, Jaime Gil de Biedma, Pere Gimferrer, Alberto Girri, Ulalume González de León, Juan Goytisolo, Roberto Juarroz, Juan Liscano, Eduardo Lizalde, Enrique Molina, Alvaro Mutis, Silvina Ocampo, Olga Orozco, José Miguel Oviedo, Gonzalo Rojas, Alejandro Rossi, Alberto Ruy Sánchez, Severo Sarduy, Fernando Savater, Tomás Segovia, Guillermo Sucre, José Miguel Ullán, Mario Vargas Llosa, Ida Vitale, Ramón Xirau e Gabriel Zaid.
}

Revista Eletrônica da ANPHLAC, n.10, p. 126-145, jan./jun. 2011. http://revista.anphlac.org.br/index.php/revista 
Octavio Paz reconheceu a novidade da situação, e propôs uma reforma eleitoral como saída para a tensão que havia se criado com os protestos do PAN e do movimento cardenista. Paz defendeu que tanto o PRI quanto os partidos de oposição deveriam fazer um acordo em função da reforma eleitoral, de modo que todos os partidos assumissem um "compromisso com a democracia". Para Paz, esse compromisso consistia em aceitar o governo de Salinas de Gortari, estabelecendo-se o fim da oposição nas ruas e o início de uma oposição no Congresso (PAZ, 1988, p. 46).

O ponto alto desse debate na revista se deu no fim dos anos 80 , com o governo de Carlos Salinas de Gortari. Enquanto Octavio Paz apreciou o processo de modernização promovido por Salinas de Gortari, Gabriel Zaid e Enrique Krauze continuaram a criticar sistematicamente o governo e a gestão feita pelo PRI. Krauze insistia que o México necessitava de uma reforma política e de uma "democracia sem adjetivos". Alinhados, Octavio Paz e Adolfo Castañon publicaram um comentário sobre o Fondo Nacional para la cultura y las artes, criado pelo governo Salinas de Gortari em 1989. O comentário introdutório esclarecia que a criação do fundo era a realização de um antigo projeto esboçado nas páginas de Plural (número 49, em outubro de 1975) e reproduzido em Vuelta (número 146, em janeiro de 1989), que congregaria diversos escritores financiados com recursos da iniciativa privada e do Estado.

Dirigida por Victor Flores Olea, a Comissão de Artes e Letras contou com a participação de muitos intelectuais, dentre eles Octavio Paz, Julieta Campos, Héctor Aguilar Camín, Carlos Monsiváis, Alejandro Rossi, Rufino Tamayo. Havia ainda uma comissão consultiva formada por escritores e artistas jovens, como Adolfo Castañón, Alberto Ruy Sánchez, Juan Villoro, entre outros. Tais comissões seriam renovadas após quatro anos, com a eleição de novos membros pelos seus representantes (PAZ, CASTAÑón, 1989, p. 50). Ora, as criações desses conselhos e do Fondo Nacional para la cultural y las artes faziam parte de um esforço do governo Salinas de Gortari de aproximação com diversos setores de intelectuais, com o objetivo de ganhar o apoio desses grupos para o seu projeto de modernização do país.

Octavio Paz e Adolfo Castañon também publicaram em Vuelta o discurso que haviam proferido diante do presidente da República na cerimônia de oficialização do

\footnotetext{
${ }^{9}$ Enrique Krauze analisou o governo de Carlos Salinas de Gortari em seu trabalho La presidencia imperial (1997). A transição para a democracia na América Latina e o papel do intelectual nesse contexto foram refletidos nos estudos de Maria Ligia Prado, Gabriela Pellegrino Soares e Sylvia Colombo (2007).
}

Revista Eletrônica da ANPHLAC, n.10, p. 126-145, jan./jun. 2011. 
novo órgão cultural. Nesse discurso, ficava claro o apoio de Paz ao governo de Carlos Salinas de Gortari:

Las novedades más visibles son las de orden político y económico: pluralismo democrático y modernización económica. Los cambios en los dominios de la cultura, menos ostensibles, no son menos decisivos. La acción de estos cambios es profunda y a largo plazo: modificar por dentro a las sociedades y sin ellos las otras reformas políticas terminan por disiparse (PAZ, 1989, p. 50).

O apoio de Octavio Paz ao governo de Salinas de Gortari gerou tensões entre os colaboradores de Vuelta. Fruto dessas diferenças, nos anos 90 houve uma crise na equipe de direção da revista, primeiro, com a saída de Gabriel Zaid da administração, e, depois, com a saída de Krauze da subdireção de Vuelta (CASTAÑón, 1999, p. 520521). ${ }^{10}$.

Apesar de Paz ter se aproximado do governo de Salinas de Gortari e efetivado algumas de suas propostas para o meio cultural, como, por exemplo, a criação do Conselho Nacional para a Cultura e as Artes, os cargos oficiais foram ocupados majoritariamente por intelectuais do grupo da Revista Nexos, dirigida por Héctor Aguilar Camín. O que se seguiu foi uma verdadeira "guerra de revistas" entre Vuelta e Nexos, gerando uma grande cisão no meio intelectual mexicano visível ao longo dos $\operatorname{anos} 90 .^{11}$

O debate sobre o papel do intelectual no México foi um tema bastante recorrente quer nas páginas de Plural, quer nas de Vuelta. O compromisso dos escritores e artistas variou muito tanto em relação às causas sociais, quanto às questões de crítica e independência aos governos do PRI e aos partidos políticos. Houve também alguns casos de apoio a certos governos, como os exemplos já citados de Carlos Fuentes a Luís Echeverría, e de Octavio Paz a Carlos Salinas de Gortari. Tanto o apoio de Fuentes, como o de Paz, muitos anos depois, aos governos do PRI provocaram amplas tensões e fissuras no meio cultural mexicano. No entanto, a pluralidade e a defesa da "liberdade"

\footnotetext{
${ }^{10}$ Segundo entrevista concedida por Enrique Krauze, não houve essa crise na direção da revista Vuelta nos anos 90, mas ele resolveu se afastar da direção para cuidar de seus projetos pessoais de edição de livros (KRAUZE, 2010).

${ }^{11}$ As disputas entre os grupos de intelectuais ligados a revista Vuelta e a revista Nexos foram objetos das pesquisas de Karina Malpica Valadez, Alma Lídia Cardenas Sanchez e Nancy Benitez Amaro. Esses trabalhos mostraram como tais rivalidades levaram os dois grupos a realizar distintos Congressos. Vuelta organizou, em 1990, o congresso El siglo XX: la experiencia de la libertad, que foi transmitido pela Televisa, enquanto Nexos realizou, em 1992, um colóquio de inverno Grandes cambios de nuestro tiempo: la situación internacional, América Latina y México na Unam (MALPICA VALADEZ, 1995; CARDENAS SANCHEZ, BENITEZ AMARO, 1998).
}

Revista Eletrônica da ANPHLAC, n.10, p. 126-145, jan./jun. 2011. http://revista.anphlac.org.br/index.php/revista 
e da "democracia" continuaram como eixos fundamentais de ambas as publicações, garantindo que os debates e as polêmicas dessem sempre o tom nessas revistas dirigidas por Octavio Paz.

\section{Bibliografia}

CARDENAS SANCHEZ, Alma Lidia; AMARO, Nancy Benitez. Análisis comparativo de las revistas culturales Vuelta y Nexos: parte integrante de la definición del periodismo cultural mexicano. 1998. Tese (Licenciatura em Ciências da Comunicação) - Faculdade de Ciências Políticas e Sociais, Universidade Nacional Autônoma de México, Cidade do México, 1998. (Mimeografado).

CASTAÑÓN, Adolfo. Una historia personal de Vuelta. In: SOSNOWSKI, Saúl (Org.). La cultura de un siglo. Madri; Buenos Aires: Alianza Editorial, 1999.

COSTA, Adriane Vidal. Intelectuais, política e literatura na América Latina: o debate sobre revolução e socialismo em Cortazar, García Márquez e Vargas Llosa (19582005). 2009. Tese (Doutorado) — Faculdade de Filosofia e Ciências Humanas, Universidade Federal de Minas Gerais, Belo Horizonte, 2009. (Mimeografado).

FLORES, Malva. Un cuartel general hispanoamericano. Inicio y consolidación de la revista Vuelta. IN: CRESPO, Regina (Coord.). Revistas en América Latina: proyectos literarios, políticos y culturales. Ciudad de México: Ed. Eón; CIALC; UNAM, 2010. p. 503-536.

FUENTES, Carlos. Opciones críticas en el verano de nuestro descontento. Plural, Ciudad de México, n. 11, p. 3-9, agosto 1972a.

FUENTES, Carlos et al. México 1972. Los escritores y la política. Plural, Ciudad de México, n. 13, suplemento 13, p. 28-29, oct. 1972 b.

GARCÍA PONCE, Juan et al. México 1972. Los escritores y la política. Plural, Ciudad de México, n. 13, suplemento 13, p. 26, oct. 1972.

GARCÍA TERRÉS, Jaime et al. México 1972. Los escritores y la política. Plural, Ciudad de México, n. 13, suplemento 13, p. 23, oct. 1972.

KING, John. Política en Plural (1971-1976). Letras Libres, n. 112, ano X, Ciudad de México, p. 30-39, abr. 2008.

The Role of Mexico's Plural in Latin American Literary and Political Culture.

From Tlatlelolco to the "Philantropic ogre". Nova York: Palgrav Macmillan, 2007.

Revista Eletrônica da ANPHLAC, n.10, p. 126-145, jan./jun. 2011.

http://revista.anphlac.org.br/index.php/revista 
KRAUZE, Enrique. Entrevista. Entrevistadora Sílvia Cezar Miskulin, Cidade do México, 27 de maio de 2010.

La presidencia imperial. Ascenso y caída del sistema político mexicano (19401996). Ciudad de México: Tusquets Ed., 1997.

LOAEZA, Soledad. Octavio Paz en el debate de la democratización mexicana. In: STANTON, Anthony. Octavio Paz. Entre poética y política. Ciudad de México: El Colegio de México, 2009. p. 155-198.

MALPICA VALADEZ, Karina. Construyendo consensos: Vuelta y Nexos. 1995. Tese (Licenciatura em Ciências Políticas e Administração Pública) - Escuela Nacional de Estudios Profesionales, Universidade Nacional Autônoma de México, Cidade do México, 1995. (Mimeografado).

MARQUEZ ACEVEDO, Sergio. Plural. Crítica, arte, literatura (octubre 1971-julio 1976). Estudio e índices analíticos. 1991. Tese (Licenciatura em Língua e Literatura Hispânica) — Faculdade de Filosofia e Letras, Universidade Nacional Autônoma de México, Cidade do México, 1991. (Mimeografado).

MISKULIN, Sílvia Cezar. Os intelectuais cubanos e a política cultural da Revolução (1961-1975). São Paulo: Alameda; Fapesp, 2009.

As repercussões do movimento estudantil de 1968 no México. In: Encontro da ANPHLAC, 8., 2008, Vitória. Anais eletrônicos... Vitória: UFES, 2008. Disponível em http://www.anphlac.org

MONSIVAIS, Carlos et al. México 1972. Los escritores y la política. Plural, Ciudad de México, n. 13, suplemento 13, p. 24, oct. 1972.

La cultura en México, n. 548, 9 de agosto de 1972 apud SÁNCHEZ SUSAREY, Jaime. El debate político e intelectual en México. México: Grijalbo, 1993. MONTOYA RAMÍREZ, Enrique (Org.). Octavio Paz. La Semana del Autor Octavio Paz. Madrid, 9-12 de mayo de 1988. Madrid: Instituto de Cooperación Iberoamericana; Ediciones de Cultura Hispánica; Agencia Española de Cooperación Internacional, 1989. p. 119.

PACHECO, José Emilio et al. México 1972. Los escritores y la política. Plural, Ciudad de México, n. 13, suplemento 13, p. 25, oct. 1972.

PAZ, Octavio. Cartas a Tomás Segovia (1957-1985). Ciudad de México: Fondo de Cultura Económica, 2008. 
. Fondo Nacional para la cultura y las artes. Vuelta, Ciudad de México, n. 149, p. 50, abr. 1989.

História e prehistoria de Vuelta. In: PAZ, Marie-José; CASTAÑON, Adolfo; TORRES FIERRO, Danúbio (Org.). A treinta años de Plural (1971-1976). Ciudad de México: Fondo de Cultura Económica, 2001a. p. 16-21.

. Hora cumplida. Vuelta, Ciudad de México, n. 143, p.46, oct. 1988.

. La letra y el cetro. Plural, Ciudad de México, n. 13, p. 7, oct. 1972a.

. Octavio Paz: política, literatura, moral. In: PAZ, Marie-José; CASTAÑON,

Adolfo; TORRES FIERRO, Danúbio. A treinta años de Plural (1971-1976). Ciudad de

México: Fondo de Cultura Económica, 2001b. p. 7-15.

Editorial. Vuelta, Ciudad de México, n.1, p. 4, dic. 1976.

PAZ, Octavio et al. México 1972. Los escritores y la política. Plural, Ciudad de México, n. 13, suplemento 13, p. 21, oct. 1972b.

PAZ, Octavio; CASTAÑÓN, Adolfo. Fondo Nacional para la cultura y las artes. Ciudad de México, Vuelta, n. 149, p. 50, abr. 1989.

PAZ, Octavio; RÍOS, Julián. Solo a dos voces. Ciudad de México: Fondo de Cultura Económica, 1999.

PIACENTINI, Tânia Maria. Vuelta uma revista de autor. 1996. Tese (Doutorado) Faculdade de Educação, Unicamp, Campinas, 1996. (Mimeografado).

PRADO, Maria Ligia Coelho; SOARES, Gabriela Pellegrino; COLOMBO, Sylvia. Reflexões sobre a democracia na América Latina. São Paulo: Senac, 2007.

SÁNCHEZ SUSARREY, Jaime. El seis de julio. Vuelta, Ciudad de México, n. 141, p. 62, agosto 1988 .

SEGOVIA, Tomás el al. México 1972. Los escritores y la política. Plural, Ciudad de México, n. 13, suplemento 13, p. 24, oct. 1972.

SCHERER GARCÍA, Julio. Un testimonio. In: PAZ, Marie-José; CASTAÑON, Adolfo; TORRES FIERRO, Danúbio. A treinta años de Plural (1971-1976). Ciudad de México, Fondo de Cultura Económica, 2001. p. 3.

VILLORO, Luis el al. México 1972. Los escritores y la política. Plural, Ciudad de México, n. 13, suplemento 13, p. 23, oct. 1972.

VOLPI, Jorge. La imaginación y el poder. Una historia intelectual de 1968. Ciudad de México: Era, 2008. 
ZAID, Gabriel. Carta a Carlos Fuentes. Plural, Ciudad de México, n. 12, p. 52, sept. 1972a.

ZAID, Gabriel et al. México 1972. Los escritores y la política. Plural, Ciudad de México, n. 13, suplemento 13, p. 22, oct. 1972 b. 